Article

\title{
Use of Empirical Correlations to Determine Solvent Effects in the Solvolysis of $S$-Methyl Chlorothioformate
}

\author{
Malcolm J. D’Souza ${ }^{1, *}$, Stefan M. Hailey ${ }^{1,}$ and Dennis N. Kevill ${ }^{2, *}$
}

1 Department of Chemistry, Wesley College, 120 N. State Street, Dover, Delaware 19901-3875, USA

2 Department of Chemistry and Biochemistry, Northern Illinois University, DeKalb, Illinois 60115-2862, USA

* Authors to whom correspondence should be addressed; E-Mails: dsouzama@wesley.edu (M.J.D.); dkevill@niu.edu (D.N.K.).

Received: 5 May 2010; in revised form: 12 May 2010 / Accepted: 24 May 2010 /

Published: 25 May 2010

\begin{abstract}
The specific rates of solvolysis of $S$-methyl chlorothioformate (MeSCOCl) are analyzed in 20 solvents of widely varying nucleophilicity and ionizing power at $25.0{ }^{\circ} \mathrm{C}$ using the extended Grunwald-Winstein Equation. A stepwise $S_{N} 1\left(D_{N}+A_{N}\right)$ mechanism is proposed in the more ionizing solvents including six aqueous fluoroalcohols. In these solvents, a large sensitivity value of 0.79 towards changes in solvent nucleophilicity $(l)$ is indicative of profound rearside nucleophilic solvation of the developing carbocation. In twelve of the more nucleophilic pure alchohols and aqueous solutions, the sensitivities obtained for solvent nucleophilicity $(l)$ and solvent ionizing power $(m)$ are similar to those found in acyl chlorides where an association-dissociation $\left(\mathrm{A}_{\mathrm{N}}+\mathrm{D}_{\mathrm{N}}\right)$ mechanism is believed to be operative.
\end{abstract}

Keywords: solvolysis; nucleophilicity; ionizing power; S-methyl chlorothioformate; chloroformates; thioesters; thiochloroformate; Grunwald-Winstein Equation; Linear Free Energy Relationships

\section{Introduction}

Six decades ago, Grunwald and Winstein proposed the simple linear free energy relationship (LFER) [1] to correlate the specific rates of solvolysis of initially neutral substrates reacting by an 
ionization $\left(\mathrm{S}_{\mathrm{N}} 1+\mathrm{E} 1\right)$ mechanism. In the simple Grunwald-Winstein Equation (Equation 1$), k$ and $k_{o}$ are the specific rates of solvolysis in a given solvent and in the standard solvent ( $80 \%$ ethanol), respectively, $c$ is a constant (residual) term, and $m$ represents the sensitivity to changes in the solvent ionizing power $Y$ (initially set at unity for tert-butyl chloride solvolyses) [1]. For a leaving group X, it was realized [2,3] that this requirement is closely satisfied by adamantyl derivatives RX (where $\mathrm{R}=1$ - or 2-adamantyl) and a series of $Y_{X}$ scales are now available [4]. For bimolecular nucleophilically solvent- assisted ( $\mathrm{S}_{\mathrm{N}} 2$ and/or E2) reactions, this correlation was later extended (Equation 2) by Grunwald, Winstein, and Jones [5] to include a term governed by the sensitivity $l$ to changes in solvent nucleophilicity $(N)$. Based on the reasonable assumption that primary methyl substrates in solvolysis reactions would be subject to intense nucleophilic solvent assistance, Schadt, Bentley, and Schleyer [6] used methyl p-toluenesulfonate, to arrive at the $N_{O T s}$ scale. Kevill and Anderson proposed a $N_{T}$ scale based on the solvolyses of $S$-methyldibenzothiophenium ion [7] in which the leaving group is a neutral molecule, which is little influenced by solvent change, and these values $[7,8]$ have become the recognized standards for considerations of solvent nucleophilicity. In spite of the cautionary comments regarding the use of multiparameter Equations due to the strong covariances observed between the $N$ and $Y$ values [9], the benefits gained from the application of Equations 1 and 2 to substrates with localized charges [10] have been immensely useful and accurate in predicting reaction pathways in such correlation type analysis. However, dispersions were often observed [11,12] in Grunwald-Winstein correlations when resonance delocalization was possible between the reaction site and an adjacent $\pi$-system. Additionally, scatter in Equations 1 and 2 was heightened for solvolyses of $\alpha$-haloalkyl aryl compounds that proceed via anchimeric assistance $\left(k_{\Delta}\right)$ [13]. In consideration of a number of factors, Kevill, and D'Souza proposed a solution [10,14-25] by adding an additional term, the aromatic ring parameter $I$ to Equations 1 and 2. In Equations 3 and 4, $h$ represents the sensitivity of solvolyses to changes in the aromatic ring parameter $I$. Hence, the magnitudes of the $l, m$, and $h$ values can give important indications regarding the mechanism of solvolysis [10,14-25]. Two years ago, Martins et al. after evaluating their results obtained on using the $h I$ term for substrates that (mostly) lacked $\pi$-electrons, suggested that the $I$ scale may indeed include a nucleophilic component [26]. In a recent review [27] of 30 highly hindered substrates not having appropriately placed $\pi$-electrons, we determined that in such substrates the sometimes positive and sometimes negative $h$ values that Martins observed [26] is an artifact resulting from the multicollinearity that is present between the $I$ values and a linear combination of $N_{\mathrm{T}}$ and $Y_{\mathrm{X}}$ values [27]. We have also just demonstrated that the $I$ scale is very useful in studies of the solvolyses of compounds containing a double bond in the vicinity of any developing carbocation [28].

$$
\begin{aligned}
& \log \left(k / k_{o}\right)=m Y+c \\
& \log \left(k / k_{o}\right)=I N+m Y+c \\
& \log \left(k / k_{o}\right)=m Y+h I+c \\
& \log \left(k / k_{o}\right)=I N+m Y+h I+c
\end{aligned}
$$


Thioesters are important biological molecules [29] that can undergo hydrolysis or additional molecular interactions to afford the desired thiol functionality. Furthermore, a "one-pot" synthesis method for $S$-methyl thioesters has been developed by reacting $S$-methyl chlorothioformate (MeSCOCl, 1) with carboxylic acids [30] to build combinatorial libraries to search for new commercial flavors and/or identification of characteristic flavors in foods [31]. To gain a better understanding of the relationship between the reactivity of thioesters and their structural conformations, Queen et al. [32] made a comparison of the dipole moments of a series of aryl and alkyl thiochloroformate esters to their chloro- and fluoroformate analogs in the non-polar solvent benzene. They concluded [32] that such thio- and halo-formate esters prefer a configuration where the halogen atom is in a cis position with respect to the alkyl group. Based on observations of the relationship between the atomic charges and dipole moments calculated by the semi-empirical CNDO/2 molecular orbital method, Lee [33] proposed that the alkyl chloro-, thiochloro-, thiofluoro-, thiono-, and dithio-formate esters prefer a configuration that brings the halogen into a trans position with respect to the alkyl group. More recently a number of groups [34-41] using a variety of computational studies, experimental techniques, and crystal structure analysis have confirmed Lee's original proposal [33] that the most stable geometric structures and conformations of the chloroformate (ROCOCl), thiochloroformate (RSCOCl), thiofluoroformate (ROCOF), chlorothionoformate ( $\mathrm{ROCSCl}$ ), and dithiochloroformate $(\mathrm{RSCSCl}$ ) esters exist in a configuration where the $\mathrm{C}=\mathrm{O}$ or $\mathrm{C}=\mathrm{S}$ is syn with respect to the alkyl or aryl moiety; i.e., the halogen atom is in a trans position with respect to the alkyl or aryl group. In Figure 1, the syn conformer of $\mathrm{MeSCOCl}(\mathbf{1})$ is shown as 1', whereas that of methyl chloroformate (MeOCOCl, 2) is shown as 2 '.

Figure 1. Molecular structures of $S$-methyl chlorothioformate (1), and methyl chloroformate (2). 3-D images for the syn conformer of $S$-methyl chlorothioformate (1'), and methyl chloroformate (2').

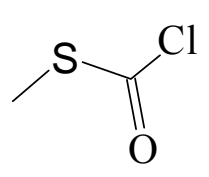

1

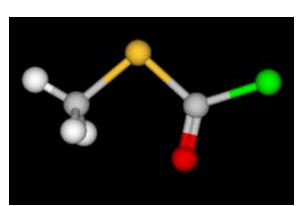

$1^{\prime}$

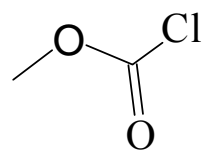

2

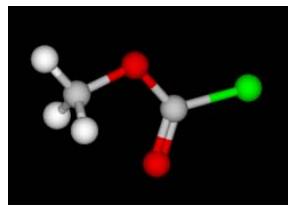

$\mathbf{2}^{\prime}$

A number of groups have now offered the conclusive explanation [32,33,43-47] that due to the increased initial ground-state resonance stabilization $\mathrm{ROCOCl}, \mathrm{RSCOCl}, \mathrm{ROCSCl}$, and RSCSCl undergo solvolytic reactions much more slowly than other acid chlorides ( $\mathrm{RCOCl}$ ). On analyzing the rate data for a series of alkyl chloro-, thio-, thiono-, and dithio-formate esters, Queen et al proposed $[44,45]$ that the thio- containing substrates hydrolyze by a unimolecular process, whereas their chloroformate counterparts tend to favor a bimolecular mechanism. Lee et al. [48,49] studied the solvolysis of $\mathbf{2}$ and its thio- analogs in a variety of aqueous ethanol, methanol, acetone, and acetonitrile mixtures and concluded that the dithio $\mathrm{MeSCSCl}$ underwent unimolecular solvolysis in all solvents, whereas the solvolyses of 2 followed a $\mathrm{S}_{\mathrm{N}} 2$ process. Additionally the authors proposed competing channels for $\mathrm{MeSCOCl}$ and $\mathrm{MeOCSCl}$ that depended on the ionizing ability of the solvent; with a $\mathrm{S}_{\mathrm{N}} 2$ mechanism favored in ethanol rich mixtures that gradually switched over to a $\mathrm{S}_{\mathrm{N}} 1$ process in the water- 
rich regions. Lee's group also advocated [50] for a concerted process for the aminolysis of aryl chlorothionoformates with aniline in acetonitrile. Castro, Santos and co-workers [51-56] followed the kinetics of several thiol, dithio, and thiono analogs of carboxylic acids with different nucleophiles spectrophotometrically. Their results [51-56] are consistent with a stepwise scheme which involves a kinetically significant proton transfer from a zwitterionic to a thermodynamically favorable anionic tetrahedral intermediate.

In an advancing assessment into the practicality of Equations 1-4 for studies of solvolytic mechanisms [10,27,57], we have previously demonstrated [58-61] that there is a side-by-side operation of the association-dissociation $\left(\mathrm{A}_{\mathrm{N}}+\mathrm{D}_{\mathrm{N}}\right)$ and ionization $\left(\mathrm{S}_{\mathrm{N}} 1\right)$ pathways in the ethyl- and phenyl- thio, and phenyl-thiono analogs of carboxylic acid esters. We also showed that the phenyl dithio ester $\mathrm{PhSCSCl}$, progresses at one extreme with strong nucleophilic solvation of a resonance stabilized carbocation [60,61], whereas, phenyl chloroformate (PhOCOCl), solvolyses by an addition-elimination $\left(A_{N}+D_{N}\right)$ pathway with the addition step being rate-determining [61,62]. Koo, Lee, and coworkers proposed the presence of a through conjugation of the ring $\pi$ system with the reaction center in phenyl chlorothionoformate (PhOCSCl) [63], and $\mathrm{PhSCSCl}$ [64]. This opinion [63] for PhOCSCl was negated [61], as no evidence was found requiring inclusion of the $h$ parameter for ionization reactions with PhOCSCl. For PhSCSCl [61], the large $l$ values of 0.69 (Equation 2) or 0.80 (Equation 4) indicated a high degree of nucleophilic solvation to the ionization process, with $m$ values of 0.95 (Equation 2 ) or 1.02 (Equation 4). The $h$ value of $0.42 \pm 0.15$ obtained [61] with use of Equation 4 had only a 0.009 probability that the $h I$ term is statistically insignificant, which suggested that the contribution from the hI term cannot be rejected [61,64]. The observations [58] that ethyl chloroformate (EtOCOCl) and ethyl thiochloroformate $(\mathrm{EtSCOCl})$ proceeded by dual competing reaction channels that are heavily dependent on solvent ionizing ability coupled with evidence that $\mathrm{MeOCOCl}$ [65] followed an additionelimination pathway in all solvents except in 90\% 1,1,1,3,3,3-hexafluoro-2-propanol (HFIP), strongly suggest that more profound variations in the dominant mechanism may occur with the sulfur-foroxygen substitution in ROCOCl [58-65]. Furthermore, it has been reported that the solvolysis of 2-thiophenecarbonyl chloride progresses in a unimolecular [66] fashion whereas the oxygen-for-sulfur substitution within the thiophene ring yields 2-furancarbonyl chloride which advances via a bimolecular addition-elimination process [67]. The present investigation continues to evaluate these trends seen in the solvolysis of thiochloroformate esters and we now report on the kinetics at $25.0{ }^{\circ} \mathrm{C}$ for the solvolyses of $\mathrm{MeSCOCl}(\mathbf{1})$ including those in solvents having an appreciable fluoroalcohol component.

\section{Results and Discussion}

The first-order specific rates of solvolysis for $\mathbf{1}$ were determined in 19 solvents at $25.0^{\circ} \mathrm{C}$. The solvents consisted of methanol $(\mathrm{MeOH})$, ethanol $(\mathrm{EtOH})$, and binary mixtures of water with methanol, ethanol, acetone, 2,2,2-trifluoroethanol (TFE), or HFIP, plus binary mixtures of TFE with ethanol. Additionally values in $100 \mathrm{EtOH}$ and $80 \mathrm{EtOH}$ were measured at $30.0{ }^{\circ} \mathrm{C}$, values in $100 \mathrm{EtOH}$, $80 \mathrm{EtOH}, 100 \mathrm{MeOH}, 80 \mathrm{MeOH}$, and $90 \mathrm{HFIP}$ were measured at $35.0^{\circ} \mathrm{C}$, and a value for $90 \mathrm{HFIP}$ was also obtained at $45.0{ }^{\circ} \mathrm{C}$. From literature values for the specific rates of solvolysis at several other temperatures, the Arrhenius Equation was used to calculate values at $25.0{ }^{\circ} \mathrm{C}$ for solvolyses in water 
[44]. The rate data for 1 in 20 solvents together with the literature values for $N_{\mathrm{T}}[7,8]$ and $Y_{\mathrm{Cl}}[4,68]$ are reported below in Table 1 .

Table 1. Specific rates of solvolysis $(k)$ of 1 , in several binary solvents at $25.0{ }^{\circ} \mathrm{C}$ and literature values for $\left(N_{T}\right)$ and $\left(Y_{C l}\right)$.

\begin{tabular}{|c|c|c|c|}
\hline Solvent $(\%)^{a}$ & $1 @ 25.0^{\circ} \mathrm{C} ; 10^{5} \mathrm{k}, \mathrm{s}^{-1 b}$ & $N_{T}^{c}$ & $Y_{C l}^{d}$ \\
\hline $100 \% \mathrm{MeOH}$ & $2.00 \pm 0.07^{e}$ & 0.17 & -1.2 \\
\hline $90 \% \mathrm{MeOH}$ & $4.29 \pm 0.15$ & -0.01 & -0.20 \\
\hline $80 \% \mathrm{MeOH}$ & $6.75 \pm 0.27^{f}$ & -0.06 & 0.67 \\
\hline $100 \% \mathrm{EtOH}$ & $0.884 \pm 0.021^{g}$ & 0.37 & -2.50 \\
\hline $90 \% \mathrm{EtOH}$ & $1.45 \pm 0.15$ & 0.16 & -0.90 \\
\hline $80 \% \mathrm{EtOH}$ & $2.44 \pm 0.12^{h}$ & 0.00 & 0.00 \\
\hline $90 \%$ Acetone & $0.107 \pm 0.007$ & -0.35 & -2.39 \\
\hline $80 \%$ Acetone & $0.334 \pm 0.013$ & -0.37 & -0.80 \\
\hline $60 \%$ Acetone & $4.30 \pm 0.20$ & -0.52 & 1.00 \\
\hline 97\% TFE (w/w) & $0.986 \pm 0.030$ & -3.30 & 2.83 \\
\hline $90 \%$ TFE $(w / w)$ & $1.92 \pm 0.13$ & -2.55 & 2.85 \\
\hline $70 \%$ TFE $(w / w)$ & $13.2 \pm 1.5$ & -1.98 & 2.96 \\
\hline $60 \mathrm{~T}-40 \mathrm{E}$ & $0.321 \pm 0.015$ & -0.94 & 0.63 \\
\hline $50 \mathrm{~T}-50 \mathrm{E}$ & $0.333 \pm 0.017$ & -0.64 & 0.60 \\
\hline $40 \mathrm{~T}-60 \mathrm{E}$ & $0.431 \pm 0.013$ & -0.34 & -0.48 \\
\hline $20 \mathrm{~T}-80 \mathrm{E}$ & $0.537 \pm 0.016$ & 0.08 & -1.42 \\
\hline $100 \% \mathrm{H}_{2} \mathrm{O}$ & $820^{i}$ & -1.38 & 4.57 \\
\hline 97\%HFIP (w/w) & $3.21 \pm 0.15$ & -5.26 & 5.17 \\
\hline $90 \%$ HFIP (w/w) & $3.48 \pm 0.092^{j}$ & -3.84 & 4.41 \\
\hline $70 \%$ HFIP $(w / w)$ & $13.9 \pm 0.78$ & -2.94 & 3.83 \\
\hline
\end{tabular}

${ }^{a}$ Substrate concentration of ca. $0.0052 \mathrm{M}$; binary solvents on a volume-volume basis at $25.0{ }^{\circ} \mathrm{C}$, except for TFE- $\mathrm{H}_{2} \mathrm{O}$ and HFIP- $\mathrm{H}_{2} \mathrm{O}$ solvents which are on a weight-weight basis. T-E are TFE-ethanol mixtures. ${ }^{b}$ With associated standard deviation. ${ }^{c}$ Refs. $7,8 .{ }^{d}$ Refs. $4,68 .{ }^{e}$ A value of $5.26( \pm 0.03) \times 10^{-5} \mathrm{~s}^{-1}$ was obtained at $35.0^{\circ} \mathrm{C} .{ }^{f}$ A value of $22.7( \pm 1.02) \times 10^{-5} \mathrm{~s}^{-1}$ was obtained at $35.0^{\circ} \mathrm{C} .{ }^{g} \mathrm{~A}$ value of $1.46( \pm 0.18) \times 10^{-5} \mathrm{~s}^{-1}$ and a value of $2.21( \pm 0.12) \times 10^{-5} \mathrm{~s}^{-1}$ was obtained at $30.0{ }^{\circ} \mathrm{C}$ and $35.0{ }^{\circ} \mathrm{C}$ respectively. A value $1.42 \times 10^{-5} \mathrm{~s}^{-1}$ at $35.0{ }^{\circ} \mathrm{C}$ has been reported [48]. $\Delta \mathrm{H}^{\neq}=15.0 \pm 0.1 \mathrm{kcal} / \mathrm{mol}, \Delta \mathrm{S}^{\neq}=-31.2 \pm 0.3 \mathrm{cal} \mathrm{mol}^{-1} \mathrm{~K}^{-1} .{ }^{h} \mathrm{~A}$ value of $4.42( \pm 0.14) \times 10^{-5} \mathrm{~s}^{-1}$ and a value of $7.41( \pm 0.16) \times 10^{-5} \mathrm{~s}^{-1}$ was obtained at $30.0{ }^{\circ} \mathrm{C}$ and $35.0{ }^{\circ} \mathrm{C}$ respectively. $\Delta \mathrm{H}^{\neq}=19.7 \pm 0.6 \mathrm{kcal} / \mathrm{mol}, \Delta \mathrm{S}^{\neq}=-13.5 \pm 2.4 \mathrm{cal} \mathrm{mol}^{-1} \mathrm{~K}^{-1} .{ }^{i}$ Calculated from Arrhenius plots using the values at various temperatures reported in Ref. [44]. ${ }^{j} \mathrm{~A}$ value of $7.72( \pm 0.16) \times 10^{-5} \mathrm{~s}^{-1}$ and a value of $18.4( \pm 0.78) \times 10^{-5} \mathrm{~s}^{-1}$ was obtained at $35.0{ }^{\circ} \mathrm{C}$ and $45.0{ }^{\circ} \mathrm{C}$ respectively. $\Delta \mathrm{H}^{\neq}=15.1 \pm 0.7 \mathrm{kcal} / \mathrm{mol}, \Delta \mathrm{S}^{\neq}=-28.4 \pm 2.5 \mathrm{cal} \mathrm{mol}^{-1} \mathrm{~K}^{-1}$. 
Table 2. Correlation of the specific rates of reaction of $\mathbf{1}$ at $25.0{ }^{\circ} \mathrm{C}$, using the simple or extended Grunwald-Winstein Equations (Equations 1 and 2).

\begin{tabular}{|c|c|c|c|c|c|c|}
\hline Substrate & $n^{a}$ & $l^{b}$ & $m^{b}$ & $\overline{c^{c}}$ & $R^{d}$ & $F^{e}$ \\
\hline \multirow[t]{8}{*}{1} & $20^{f}$ & & $0.23 \pm 0.06$ & $-0.29 \pm 0.16$ & 0.637 & 12 \\
\hline & & $0.64 \pm 0.12$ & $0.60 \pm 0.08$ & $0.10 \pm 0.13$ & 0.879 & 29 \\
\hline & $13^{g}$ & & $0.21 \pm 0.13$ & $-0.29 \pm 0.16$ & 0.435 & 3 \\
\hline & & $1.47 \pm 0.21$ & $0.49 \pm 0.07$ & $0.14 \pm 0.09$ & 0.927 & 30 \\
\hline & $12^{h}$ & & $0.17 \pm 0.15$ & $-0.34 \pm 0.18$ & 0.341 & 1 \\
\hline & & $1.48 \pm 0.18$ & $0.44 \pm 0.06$ & $0.08 \pm 0.08$ & 0.949 & 40 \\
\hline & $8^{i}$ & & $0.24 \pm 0.26$ & $-0.30 \pm 0.97$ & 0.341 & 1 \\
\hline & & $0.79 \pm 0.06$ & $0.85 \pm 0.07$ & $-0.27 \pm 0.18$ & 0.987 & 95 \\
\hline
\end{tabular}

${ }^{a}$ Using data at $25.0^{\circ} \mathrm{C}$ from Table $1 ; n$ is the number of solvents. ${ }^{b}$ With associated standard error. ${ }^{c}$ Accompanied by standard error of the estimate. ${ }^{d}$ Correlation coefficient. ${ }^{e}$ F-test value. ${ }^{f}$ All solvents. ${ }^{g}$ 100-80 EtOH- $\mathrm{H}_{2} \mathrm{O}, 100-80$ MeOH- $\mathrm{H}_{2} \mathrm{O}$, 90-60 Acetone- $\mathrm{H}_{2} \mathrm{O}$, 60T-40E, 50T-50E, 40T-60E, 20T-80E. ${ }^{h}$ 100-80 EtOH- $\mathrm{H}_{2} \mathrm{O}, 100-80$ MeOH- $\mathrm{H}_{2} \mathrm{O}, 90-80$ Acetone- $\mathrm{H}_{2} \mathrm{O}$, 60T-40E, 50T-50E, 40T-60E, 20T-80E. ${ }^{i}$ 97-70TFE- $\mathrm{H}_{2} \mathrm{O}, 97-70$ HFIP- $\mathrm{H}_{2} \mathrm{O}, \mathrm{H}_{2} \mathrm{O}, 60$ Acetone- $\mathrm{H}_{2} \mathrm{O}$.

Table 3. Correlation of the specific rates of reaction of other chloroformate and thiochloroformate esters using the extended Grunwald-Winstein Equation (Equation 2).

\begin{tabular}{cccccccc}
\hline Substrate & $\boldsymbol{n}^{\boldsymbol{a}}$ & $\boldsymbol{l}^{\boldsymbol{b}}$ & $\boldsymbol{m}^{\boldsymbol{b}}$ & $\boldsymbol{l} \boldsymbol{m}$ & $\boldsymbol{c}^{\boldsymbol{c}}$ & $\boldsymbol{R}^{\boldsymbol{d}}$ & $\boldsymbol{F}^{\boldsymbol{e}}$ \\
\hline $\mathrm{EtOCOCl}^{f}$ & 28 & $1.56 \pm 0.09$ & $0.55 \pm 0.03$ & 2.84 & $0.19 \pm 0.24$ & 0.967 & 179 \\
& 7 & $0.69 \pm 0.13$ & $0.82 \pm 0.16$ & 0.84 & $-2.40 \pm 0.27$ & 0.946 & 17 \\
$\mathrm{MeOCOCl}^{g}$ & 19 & $1.59 \pm 0.09$ & $0.58 \pm 0.05$ & 2.74 & $0.16 \pm 0.07$ & 0.977 & \\
$\mathrm{PhOCOCl}^{h}$ & 49 & $1.66 \pm 0.05$ & $0.56 \pm 0.03$ & 2.96 & $0.15 \pm 0.07$ & 0.980 & 568 \\
$\mathrm{PhSCSCl}^{i}$ & 31 & $0.69 \pm 0.05$ & $0.95 \pm 0.03$ & 0.73 & $0.18 \pm 0.05$ & 0.987 & 521 \\
$\mathrm{PhOCSCl}^{j}$ & 9 & $1.88 \pm 0.28$ & $0.56 \pm 0.15$ & 3.36 & $0.38 \pm 0.15$ & 0.950 & 28 \\
& 18 & $0.34 \pm 0.05$ & $0.93 \pm 0.09$ & 0.37 & $-2.54 \pm 0.34$ & 0.955 & 77 \\
$\mathrm{PhSCOCl}^{k}$ & 16 & $1.74 \pm 0.17$ & $0.48 \pm 0.07$ & 3.63 & $0.19 \pm 0.23$ & 0.946 & 55 \\
& 6 & $0.62 \pm 0.08$ & $0.92 \pm 0.11$ & 0.67 & $-2.29 \pm 0.13$ & 0.983 & 44 \\
$\mathrm{EtSCOCl}^{l}$ & 19 & $0.66 \pm 0.08$ & $0.93 \pm 0.07$ & 0.71 & $-0.16 \pm 0.31$ & 0.961 & 96 \\
$\mathrm{MeOCOF}^{m}$ & 14 & $1.33 \pm 0.09$ & $0.73 \pm 0.06$ & 1.82 & $-0.08 \pm 0.08$ & 0.972 & \\
\hline
\end{tabular}

${ }^{a} n$ is the number of solvents. ${ }^{b}$ With associated standard error. ${ }^{c}$ Accompanied by standard error of the estimate. ${ }^{d}$ Correlation coefficient. ${ }^{e}$ F-test value. ${ }^{f}$ Values taken from [58]. ${ }^{g}$ Values taken from [65]. ${ }^{h}$ Values taken from [61]. ${ }^{i}$ Values taken from [61]. ${ }^{j}$ Values taken from [61]. ${ }^{k}$ Values taken from [60]. ${ }^{l}$ Values taken from [58]. ${ }^{m}$ Values taken from [69].

In Table 1, the experimental first-order rate constants for the solvolysis of $\mathbf{1}$ increase as the proportion of water is increased in all the binary solvent mixtures (including fluoroalcohols) studied. These kinetic findings imply that mechanistically there is a strong dependence on solvent polarity. Using the rate data of the 20 solvents reported in Table 1, we report in Table 2 an extremely poor linear correlation using Equation 1, with $m=0.23 \pm 0.06, c=-0.29 \pm 0.16,0.637$ for the correlation coefficient, and 12 for the $F$-test value. This correlation improves marginally on use of the extended Grunwald-Winstein Equation (Equation 2) to lead to $l=0.64 \pm 0.12, m=0.60 \pm 0.08, c=0.10 \pm 0.13$, 
$R=0.879$, and 29 for the $F$-test. Comparing the rates of $\mathbf{1}$ with those previously reported [69] for $\mathbf{2}$ and methyl fluoroformate (MeOCOF) in pure $\mathrm{EtOH}$ and $\mathrm{MeOH}$ at $35.0{ }^{\circ} \mathrm{C}$, we observe a rate trend of $k_{1}<k_{2} \cong k_{\text {MeOcof }}$. The direction further shifts to $k_{1}<k_{2}<k_{\text {MeOcoF }}$ in $80 \mathrm{EtOH}$ at $35.0^{\circ} \mathrm{C}$. This signals that the inductive effect exerted by the methoxy group in 2 and in MeOCOF, makes the carbonyl carbon more positive and for the alcoholysis of 1, a bimolecular type solvent mechanism may be consequential. As shown in Table 3, the extended Grunwald-Winstein Equation (Equation 2) has proven to be a powerful tool that has been used successfully to correlate the solvolyses of chloroformate $[10,58,61,62,65,69]$ chlorothioformate [10,58,59], chlorothionoformate $[10,60,61,63]$, and chlorodithioformate $[10,60,61,64]$, esters, including instances where side-by-side mechanisms were under consideration. A plot of $\log \left(k / k_{o}\right)$ for 1 against $\log \left(k / k_{o}\right)$ for 2 in the common pure and binary solvents is shown in Figure 2. This plot validates the probability of dual competing reaction channels that is dependent on the ionizing ability of the solvent. As observed in Table 2, the extended Grunwald-Winstein analysis of the solvolysis of $\mathbf{1}$ is best carried out by dissecting the solvents based on solvent polarity. With 13 of the more nucleophilic solvents, we obtained a fair linear correlation with $l=1.47 \pm 0.21, m=0.49 \pm 0.07, c=0.14 \pm 0.09, R=0.927$, and an $F$-test value of 30 . Omitting the 60 acetone value, in 12 of the remaining nucleophilic solvents the correlation improves somewhat with $l=1.48 \pm 0.18, m=0.44 \pm 0.06, c=0.08 \pm 0.08, R=0.949$, and an $F$-test value of 40 . These values are very similar to the ones observed (Table 3 ) for the fluoro-, chloro-, and thio-chloroformate esters demonstrated [10,58-62,65,69] to solvolyze in the more nucleophilic solvents with rate-determining addition via an addition-elimination (association-dissociation) pathway. Reported in Table 1 are the activation parameters for 1 in $100 \mathrm{EtOH}$ and $80 \mathrm{EtOH}$, in particular the negative value for the entropy of activation are compatible with those expected for a bimolecular process. Furthermore, the $l / m$ ratio of 3.36 for 1 is analogous to the $l / m$ ratio shown in Table 3 of $\mathrm{PhSCOCl}$ and $\mathrm{PhOCSCl}$, which suggests that there exists a similar pattern of behavior between the specific rates of solvolysis in the more nucleophilic solvents in $\mathbf{1}, \mathrm{PhSCOCl}$ and $\mathrm{PhOCSCl}$. The plot of $\log \left(k / k_{\mathrm{o}}\right) \mathbf{1}$ against $1.48 N_{\mathrm{T}}+0.44 Y_{\mathrm{Cl}}$ shown in Figure 3 illustrates the two distinct mechanisms and advocates the possibility of a superimposed unimolecular pathway for 60 acetone. Using the Equation $\log \left(k / k_{\mathrm{o}}\right)=1.44 N_{\mathrm{T}}+0.44 Y_{\mathrm{Cl}}+0.08$, we calculate the specific rate by the bimolecular additionelimination mechanism in 60 acetone to be $1.37 \times 10^{-5}$. This signifies that 1 does solvolyze in 60 acetone by a dual pathway, viz., $32 \%$ bimolecular addition-elimination and $68 \%$ proceeds by an ionization mechanism.

In the highly ionizing aqueous fluoroalcohols, water, and 60 acetone, use of Equation 2 yields an excellent linear correlation with $l=0.79 \pm 0.06, m=0.85 \pm 0.07, c=-0.27 \pm 0.18, R=0.987$, and 95 for the F-test. These appreciable sensitivities towards changes in both solvent nucleophilicity and solvent ionizing power are similar to $l=0.83$, and $m=0.70$ observed for the solvolysis of acetyl chloride $[41,57,70] ; l=0.69$, and $m=0.95$ for $\mathrm{PhSCSCl}$ [61]; and $l=0.66$, and $m=0.93$ for EtSCOCl [58], systems believed to follow an ionization pathway with appreciable nucleophilic solvation of the developing carbocation. It has been shown [41] that a theoretical G3 calculation for the gas phase heterolytic bond dissociation energy of $\mathbf{1}$ is $162.6 \mathrm{kcal} / \mathrm{mol}$. This figure is almost identical to the value of $161.8 \mathrm{kcal} / \mathrm{mol}$ obtained for acetyl chloride [41] which attests to a similarity of heterolysis mechanisms for both substrates. 
Figure 2. The plot of $\log \left(k / k_{o}\right)$ for methyl chlorothioformate (1) against $\log \left(k / k_{o}\right)$ for methyl chloroformate (2) in common pure and binary solvents.

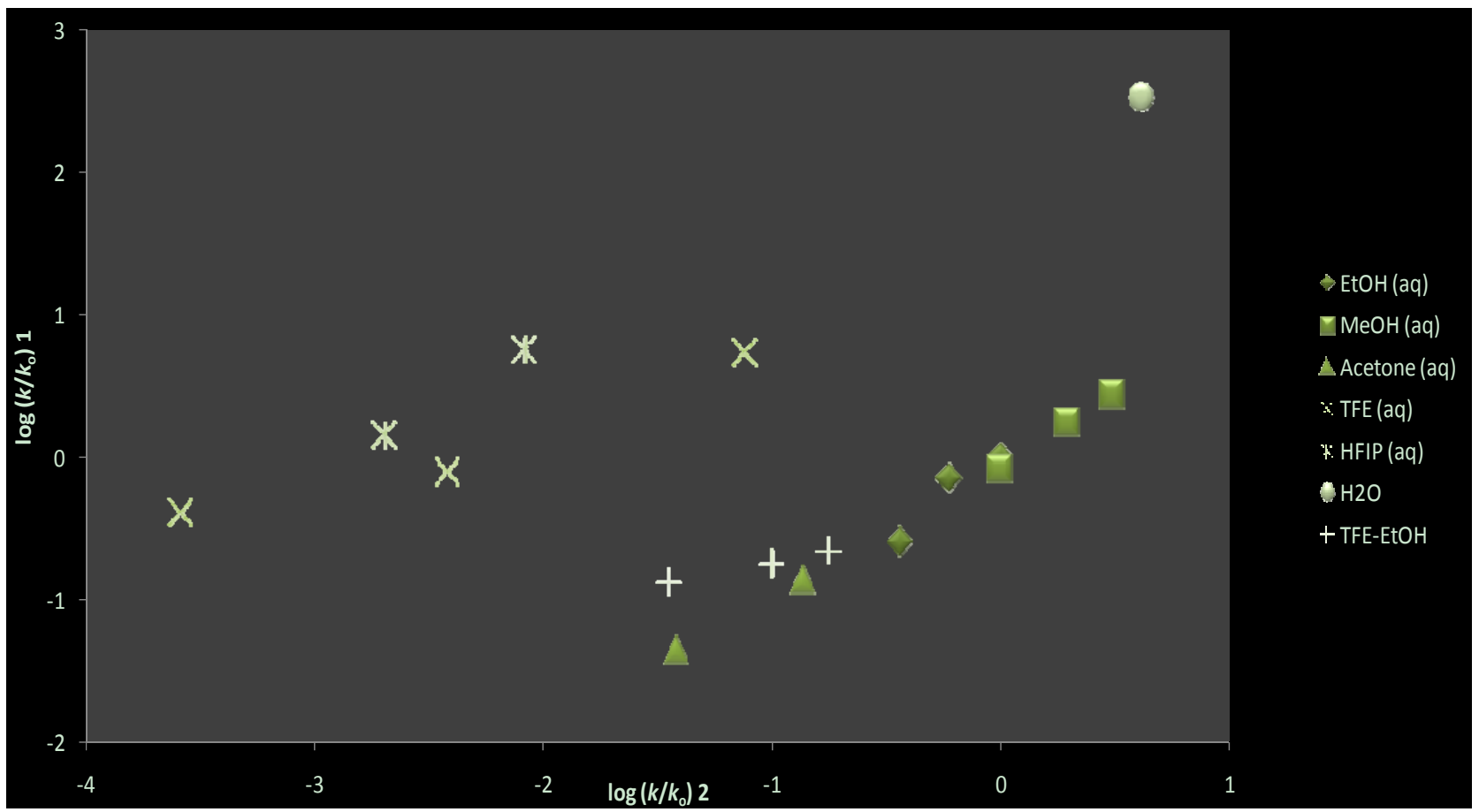

Figure 3. The plot of $\log \left(k / k_{o}\right)$ for methyl chlorothioformate (1) against $1.48 N_{\mathrm{T}}+0.44 Y_{\mathrm{Cl}}$.

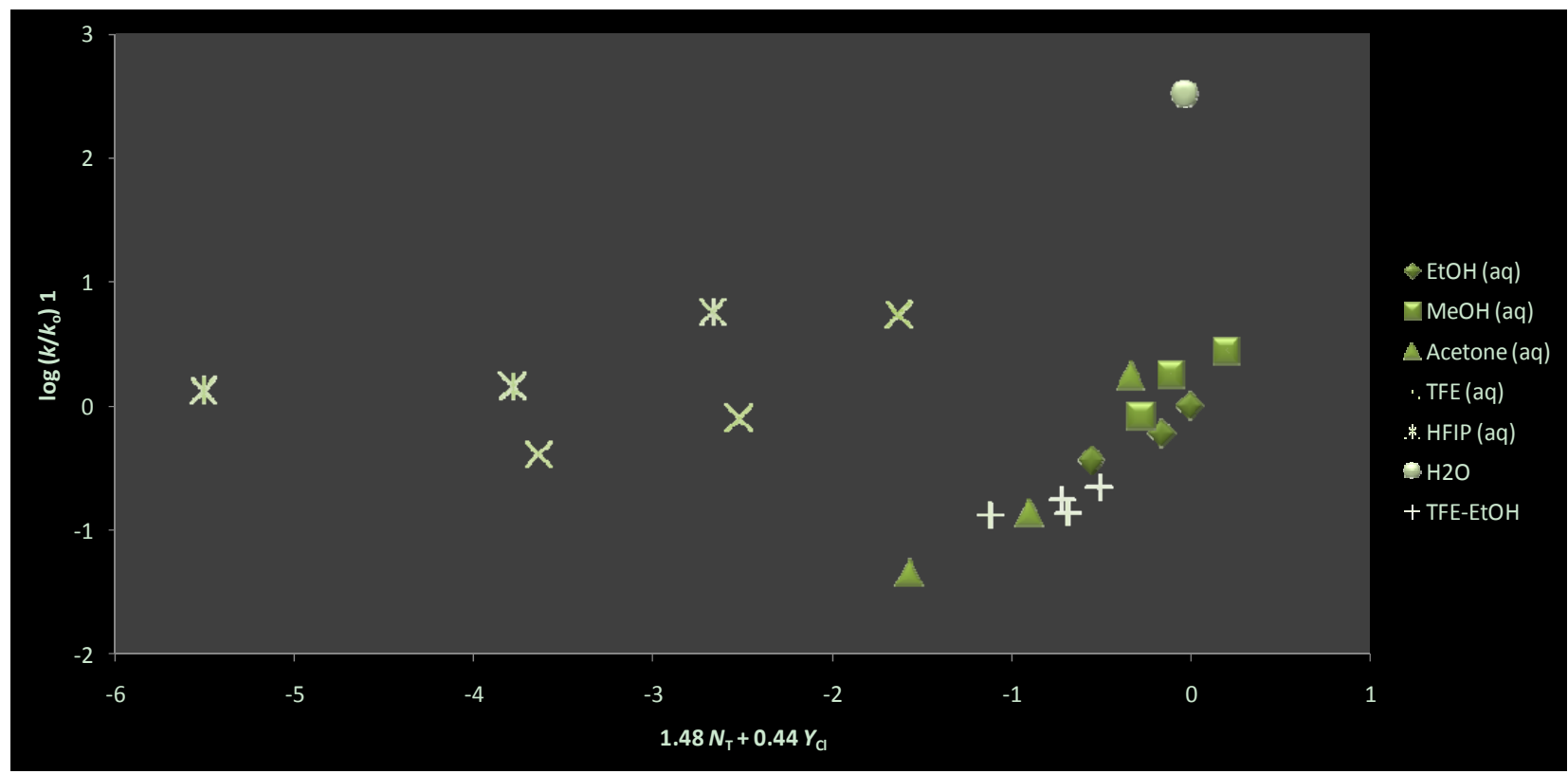

The slightly lower nucleophilic solvation requirement $(l=0.66)$ for EtSCOCl when compared to that in $1(l=0.79)$, is consistent with the additional carbon in EtSCOCl serving as a weak electrondonating substituent to stabilize the developing acylium ion. Additionally in most solvents studied (except in $100 \mathrm{EtOH}, 100 \mathrm{MeOH}$, and $90 \mathrm{MeOH}$ ), EtSCOCl solvolyzes by a stepwise ionization mechanism with strong nucleophilic solvation $(l=0.66)$ of the developing acylium ion [58]. The negative entropy of activation $\left(\Delta \mathrm{S}^{\neq}=-28.4 \pm 2.5 \mathrm{cal} \mathrm{mol}^{-1} \mathrm{~K}^{-1}\right)$ observed in 90 HFIP as reported in 
Table 1 for $\mathbf{1}$, further indicates a greater degree of ordering in the transition state than in the initial state which arises from the preferential tendency of strong rear-side solvation effects (association) at the developing carbocation.

At the other extreme, the photodecomposition of $\mathrm{MeSCOCl}(\mathbf{1})$ on irradiation with broad-band UVvisible light occurs in sequential steps [71] first forming $\mathrm{CO}$ and $\mathrm{MeSCl}$. The authors then proposed a second step entailing detachment of a hydrogen atom from the methyl group of $\mathrm{MeSCl}$ with the formation of thioformaldehyde $\left(\mathrm{H}_{2} \mathrm{C}=\mathrm{S}\right)$ and $\mathrm{HCl}[71]$.

\section{Conclusions}

The solvolysis of MeSCOCl (1) in the wide variety of solvents currently studied is found to be heavily dependent on the specific solvent properties of solvent nucleophilicity and solvent ionizing power. The empirical correlations presently carried out support the existence of concurrent side-by-side mechanisms, with a bimolecular association-dissociation (addition-elimination) mechanism favored in the more nucleophilic solvents and a stepwise ionization with profound rearside nucleophilic solvation occurring in the highly ionizing binary solvent mixtures. The extended Grunwald-Winstein Equation (Equation 2) has once again proven to be an important empirical correlation tool that is sensitive enough to evaluate the relationships between reactivity and solutesolvent interactions.

\section{Experimental Section}

The S-methyl chlorothioformate (Sigma-Aldrich, 96\%) was used as received. Solvents were purified and the kinetic runs carried out as described previously [72]. A substrate concentration of approximately $0.005 \underline{\mathrm{M}}$ in a variety of solvents was employed. For some of the runs, calculation of the specific rates of solvolysis (first-order rate coefficients) was carried out by a process in which the conventional Guggenheim treatment [73] was modified [74] so as to give an estimate of the infinity titer, which was then used to calculate for each run a series of integrated rate coefficients. The specific rates and associated standard deviations, as presented in Table 1, are obtained by averaging all of the values from, at least, duplicate runs.

Multiple regression analyses were carried out using the Excel 2007 package from the Microsoft Corporation, and the SigmaPlot 9.0 software version from Systat Software, Inc., San Jose, CA, was used for the Guggenheim treatments.

\section{Acknowledgements}

This research was supported by grant number 2 P2O RR016472-10 from the National Center for Research Resources (NCRR), a component of the National Institutes of Health (NIH). This IDeA Network of Biomedical Research Excellence (INBRE) grant to the state of Delaware was obtained under the leadership of the University of Delaware, and the authors sincerely appreciate their efforts. 


\section{References and Notes}

1. Grunwald, E.; Winstein, S. The Correlation of Solvolysis Rates. J. Am. Chem. Soc. 1948, 70, 846-854.

2. Schleyer, P.v.R.; Nicholas, R.D. The Reactivity of Bridgehead Compounds of Adamantane. $J$. Am. Chem. Soc. 1961, 83, 2700-2707.

3. Bentley, T.W.; Schleyer, P.v.R. Medium Effects on the Rates and Mechanisms of Solvolytic Reactions. Adv. Phys. Org. Chem. 1977, 14, 32-40.

4. Bentley, T.W.; Llewellyn, G. Yx Scales of Solvent Ionizing Power. Prog. Phys. Org. Chem. 1990, 17, 121-158.

5. Winstein, S.; Grunwald, E.; Jones, H.W. The Correlation of Solvolyses Rates and the Classification of Solvolysis Reactions into Mechanistic Categories. J. Am. Chem. Soc. 1951, 73, 2700-2707.

6. Schadt, F.L.; Bentley, T.W.; Schleyer, P.v.R. The $\mathrm{S}_{\mathrm{N}} 2-\mathrm{S}_{\mathrm{N}} 1$ Spectrum. 2. Quantitative Treatments of Nucleophilic Solvent Assistance. A Scale of Solvent Nucleophilicities. J. Am. Chem. Soc. 1976, 98, 7667-7674.

7. Kevill, D.N.; Anderson, S.W. An Improved Scale of Solvent Nucleophilicity Based on the Solvolysis of the S-Methyldibenzothiophenium Ion. J. Org. Chem. 1991, 56, 1845-1850.

8. Kevill, D.N. Development and Uses of Scales of Solvent Nucleophilicity. In Advances in Quantitative Structure-Property Relationships; Charton, M., Ed.; JAI Press: Greenwich, CT, USA, 1996; Volume 1, pp. 81-115.

9. Bentley, T.W.; Garley, M.S. Correlations and Predictions of Solvent Effects on Reactivity: Some Limitations of Multi-Parameter Equations and Comparisons with Similarity Models Based on One Solvent Parameter. J. Phys. Org. Chem. 2006, 19, 341-349.

10. Kevill, D.N.; D’Souza, M.J. Sixty Years of the Grunwald-Winstein Equation: Development and Recent Applications. J. Chem. Res. 2008, 61-66.

11. Bentley, T.W.; Koo, I.S.; Norman, S.J. Distinguishing Between Solvation Effects and Mechanistic Changes. Effects Due to Differences in Solvation of Aromatic Rings and Alkyl Groups. J. Org. Chem. 1991, 56, 1604-1609.

12. Liu, K.T.; Sheu, H.C. Solvolysis of 2-Aryl-2-Chloroadamantanes. A New Y scale for Benzylic Chlorides. J. Org. Chem. 1991, 56, 3021-3025.

13. Fujio, M.; Saeki, Y.; Nakamoto, K.; Yatsugi, K.; Goto, N.; Kim, S.H.; Tsuji, Y.; Rappoport, Z.; Tsuno, Y. Solvent Effects on Anchimerically Assisted Solvolyses. II. Solvent Effects in Solvolyses of threo-2-Aryl-1-methylpropyl-p-toluenesulfonates. Bull. Chem. Soc. Jpn. 1995, 68, 2603-2617.

14. Kevill, D.N.; Ismail, N.HJ.; D’Souza, M.J. Solvolysis of the (p-Methoxybenzyl)dimethyl Sulfonium Ion. Development and Use of a Scale to Correct for Dispersion in Grunwald-Winstein Plots. J. Org. Chem. 1994, 59, 6303-6312.

15. Kevill, D.N.; D’Souza, M.J. Application of the Aromatic Ring Parameter $(I)$ to the GrunwaldWinstein Treatment of the Specific Rates of Solvolysis of Substituted Naphthylmethyl and Anthrylmethyl Sufonates. Org. React. (Tartu). 1995, 29, 55. 
16. Kevill, D.N.; D’Souza, M.J. Considerably Improved Grunwald-Winstein Correlations for Solvolyses of Several Secondary and Tertiary Benzylic Derivatives upon Inclusion of a Term Governed by the Aromatic Ring Parameter (I). J. Chem. Soc., Perkin Trans. 2 1995, 973-980.

17. Kevill, D.N.; D’Souza, M.J. Incorporation of a Term Governed by the Aromatic Ring Parameter (I) into Grunwald-Winstein Correlations of the Solvolyses of Diarylmethyl, Naphthylmethyl and Arylmethyl Bromides. J. Chem. Res. Synop. 1996, 286-287; Miniprint 1996, 1649.

18. Kevill D.N.; Anderson, S.W.; Ismail, N. HJ. Correlation of the Rates of Solvolyses of the Benzhydryldimethylsulfonium Ion. Application of the Aromatic Ring Parameter. J. Org. Chem. 1996, 61, 7256-7262.

19. Kevill, D.N.; D’Souza, M.J. Application of the Aromatic Ring Parameter (I) to Solvolyses of $\beta$-Arylalkyl Toluene-p-sulfonates. J. Chem. Soc. Perkin Trans. 2 1997, 257-263.

20. Kevill, D.N.; D’Souza, M.J.; Ren, H. Correlation of the Rates of Solvolysis of Arylmethyl p-Toluenesulfonates: Application of the Aromatic Ring Parameter and a Discussion of Similarity Models. Can. J. Chem. 1998, 76, 751-757.

21. Kevill, D.N.; D'Souza, M.J. Application of the Aromatic Ring Parameter (I) to Solvolyses of Extremely Crowded Alkyl Derivatives. Tett. Lett. 1998, 39, 3973-3976.

22. Kevill, D.N.; Ismail, N. HJ. Correlation of the Rates of Solvolysis of (Arylmethyl)methylphenylSulfonium Ions. J. Chem. Soc. Perkin Trans. 2 1998, 1865-1868.

23. Kevill, D.N.; D’Souza, M.J. Concerning the Extents of Nucleophilic Participation in Solvolyses of p-Methoxybenzyl Halides. J. Chem Res. (S) 1999, 336-337.

24. Kevill, D.N.; D'Souza, M.J. Correlation of the Rates of Solvolyses of Benzoyl Chloride and Derivatives Using Extended Forms of the Grunwald-Winstein Equation. J. Phys. Org. Chem. 2002, 15, 881-888.

25. D’Souza, M.J.; Boggs, M.E.; Kevill, D.N. Correlation of the Rates of Solvolysis of 2-Furancarbonyl Chloride and Three Napthoyl Chlorides. J. Phys. Org. Chem. 2006, 19, 173-178.

26. Reis, M.C.; Elvas-Leitão, R.; Martins. F. The Influence of Carbon-Carbon Multiple Bonds on the Solvolyses of Tertiary Alkyl Halides: A Grunwald-Winstein Analysis. Int. J. Mol. Sci. 2008, 9, 1704-1716.

27. Kevill, D.N.; D’Souza, M.J. Use of the Simple and Extended Grunwald-Winstein Equations in the Correlation of the Rates of Solvolysis of Highly Hindered Tertiary Alkyl Derivatives. Cur. Org. Chem. 2010, 14, 1037-1049.

28. D’Souza, M.J.; Darington, A.M.; Kevill, D.N. On the Importance of the Aromatic Ring Parameter in Studies of the Solvolyses of Cinnamyl and Cinnamoyl Halides. Org. Chem. Int. 2010, 2, 130506:1-130506:16.

29. Wong, S.S. Chemistry of Protein Conjugation and Cross-Linking; CRC-Press: Boca Raton, FL, USA, 1991; pp. 7-51.

30. Khan, J.A.; Gijs, L.; Berger, C.; Martin, N.; Piraprez, G.; Spinnler, H.E.; Vulfson, E.N.; Collin, S. Combinatorial Approach to Flavor Analysis. 1. Preparation and Characterization of a S-Methyl Thioester Library. J. Agric. Food Chem. 1999, 47, 3269-3273.

31. Berger, C.; Martin, N.; Collin, S.; Gijs, L; Khan, J.A.; Piraprez, G.; Spinnler, H.E.; Vulfson, E.N. Combinatorial Approach to Flavor Analysis. 2. Olfactory Investigation of a Library of S-Methyl 
Thioesters and Sensory Evaluation of Selected Components. J. Agric. Food Chem. 1999, 47, 3274-3279.

32. Queen, A.; Nour, T.A.; Bock, E. Electric Moments, Sulfur Bonding, and Conformations of Substituted Thiochloroformate Esters in Benzene. Can. J. Chem. 1969, 47, 343-348.

33. Lee, I. Nucleophilic Substitution at a Carbonyl Carbon. Part II. CNDO/2 Studies on Conformation and Reactivity of the Thio-Analogues of Methyl Chloroformate. J. Korean Chem. Soc. 1972, 16, 334-340.

34. Silvia, C.J.; True, N.S.; Bohn, R.K. Low Resolution Microwave Spectroscopy. 13. Conformations of S-n-Propyl Thioesters. J. Phys. Chem. 1978, 82, 483-488.

35. Shen, Q.; Krisak, R.; Hagen, K. The Molecular Structure of Methyl Chlorothioformate by GasPhase Electron Diffraction and Microwave Spectroscopy Data. J. Mol. Struc. 1995, 346, 13-19.

36. Gobbato, K.I.; Della Védova, C.O.; Mack, H.-G.; Oberhammer, H. Structures and Conformations of (Trifluoromethyl)thioacetic Acid, $\mathrm{CF}_{3} \mathrm{C}(\mathrm{O}) \mathrm{SH}$, and Derivatives $\mathrm{CF}_{3} \mathrm{C}(\mathrm{O}) \mathrm{SCH}_{3}$ and $\mathrm{CF}_{3} \mathrm{C}(\mathrm{O}) \mathrm{SCl}$. Inorg. Chem. 1996, 35, 6152-6157.

37. So, S.P. Structures, Relative Stabilities and Barriers to Internal Rotation of Chloroformyl Hypochlorite and Thiohypochlorite. J. Mol. Struc. Theochem. 1998, 168, 217-225.

38. Ulic, S.E.; Coyanis, E.M.; Romano, R.M.; Della Védova, C.O. S-Ethyl Thiochloroformate, $\mathrm{ClC}(\mathrm{O}) \mathrm{CH}_{2} \mathrm{CH}_{3}$ : Unusual Conformational Properties? Spectrochim. Acta Part A: Mol. Biomol. Spec. 1998, 54, 695-705.

39. Romano, R.M.; Della Védova, C.O.; Downs, A.J.; Parsons, S.; Smith, S. Structural and Vibrational Properties of $\mathrm{ClC}(\mathrm{O}) \mathrm{SY}$ Compounds with $\mathrm{Y}=\mathrm{Cl}$ and $\mathrm{CH}_{3}$. New J. Chem. 2003, 27, 514-519.

40. Erben, M.F.; Della Védova, C.O.; Boese, R.; Willner, H.; Oberhammer, H. Trifluoromethyl Chloroformate: $\mathrm{ClC}(\mathrm{O}) \mathrm{OCF}_{3}$ : Structure, Conformation, and Vibrational Analysis Studied by Experimental and Theoretical Methods. J. Phys. Chem. A 2004, 108, 699-706.

41. Bentley, T.W. Structural Effects on the Solvolytic Reactivity of Carboxylic and Sulfonic Acid Chlorides. Comparisons with Gas-Phase Data for Cation Formation. J. Org. Chem. 2008, 73, 6251-6257.

42. Crunden, E.W.; Hudson, R.F. The Mechanism of Hydrolysis of Acid Chlorides. Part VII. Alkyl Chloroformates. J. Chem. Soc. 1961, 3748-3755.

43. Queen, A. Kinetics of the Hydrolysis of Acyl Chlorides in Pure Water. Can. J. Chem. 1967, 45, 1619-1629.

44. Queen, A.; Nour, T.A.; Paddon-Row, M.N.; Preston, K. Kinetics and Hydrolysis of Thiochloroformate Esters in Pure Water. Can. J. Chem. 1970, 48, 522-527.

45. McKinnon, D.M.; Queen, A. Kinetics and Mechanism for the Hydrolysis of Chlorothionoformate and Chlorodithioformate Esters in Water and Aqueous Acetone. Can. J. Chem. 1972, 50, 1401-1406.

46. Kevill D.N. Choloroformate Esters and Related Compounds. In: Patai S, editor. The Chemistry of the Functional Groups: The Chemistry of Acyl Halides; Wiley: New York, NY, USA, 1972; Chapter 12, pp. 381-453. 
47. Bentley, T.W.; Harris, H.C.; Zoon H.-R.; Gui, T.L.; Dae, D.S.; Szajda, S.R. Mechanisms of Solvolyses of Acid Chlorides and Chloroformates. Chloroacetyl and Phenylacetyl Chloride as Similarity Models. J. Org. Chem. 2005, 70, 8963-8970.

48. La, S.; Koh, K.S.; Lee, I. Nucleophilic Substitution at a Carbonyl Carbon Atom (XI). Solvolysis of Methyl Chloroformate and Its Thioanalogues in Methanol, Ethanol and Ethanol-Water Mixtures. J. Korean Chem. Soc. 1980, 24, 1-7.

49. La, S.; Koh, K.S.; Lee, I. Nucleophilic Substitution at a Carbonyl Carbon Atom (XII). Solvolysis of Methyl Chloroformate and Its Thioanalogues in $\mathrm{CH}_{3} \mathrm{CN}-\mathrm{H}_{2} \mathrm{O}$ and $\mathrm{CH}_{3} \mathrm{COCH}_{3}-\mathrm{H}_{2} \mathrm{O}$ Mixtures. J. Korean Chem. Soc. 1980, 24, 8-14.

50. Oh, H.K.; Ha, J.S.; Sung, D.D.; Lee, I. Aminolysis of Aryl Chlorothionoformates with Anilines in Acetonitrile: Effects of Amine Nature and Solvent on the Mechanism. J. Org. Chem. 2004, 69, 8219-8223.

51. Castro, E.A. Kinetics and Mechanisms of Reactions of Thiol, Thiono, and Dithio Analogues of Carboxylic Esters with Nucleophilies. Chem. Rev. 1999, 99, 3505-3524.

52. Castro, E.A.; Cubillos, M.; Santos, J.G. Kinetics and Mechanisms of the Pyridinolysis of Phenyl and 4-Nitrophenyl Chlorothionoformates. Formation and Hydrolysis of 1(Aryloxythiocarbonyl)pyridinum Cations. J. Org. Chem. 2004, 69, 4802-4807.

53. Castro, E.A.; Aliaga, M.; Gazitúa, M.; Santos, J.G. Kinetics and Mechanism of the Reactions of $S$-Methyl Chlorothioformate with Pyridines and Secondary Alicyclic Amines. Tetrahedron 2006, 62, 4863-4869.

54. Castro, E.A. Kinetics and Mechanisms of Reactions of Thiol, Thiono, and Dithio Analogues of Carboxylic Esters with Nucleophilies. An Update. J. Sulf. Chem. 2007, 28, 401-429.

55. Castro, E.A.; Aliaga, M.; Campodonico, P.R.; Leis, J.R.; García-Río, L.; Santos, J.G. Reactions of Aryl Chlorothionoformates with Quinuclidines. A Kinetic Study. J. Phys. Org. Chem. 2008, 21, 102-107.

56. Castro, E.A.; Gazitúa, M.; Santos, J.G. Kinetics and Mechanism of the Reactions of Aryl Chlorodithioformates with Pyridines and Secondary Alicyclic Amines. J. Phys. Org. Chem. 2009, 22, 1030-1037.

57. D’Souza, M.J.; Ryu, Z.H.; Park, B.-C.; Kevill, D.N. Correlation of the Rates of Solvolysis of Acetyl Chloride and $\alpha$-Substituted Derivatives. Can. J. Chem. 2008, 86, 359-367.

58. Kevill, D.N.; D'Souza, M.J. Concerning the Two Reaction Channels for the Solvolyses of Ethyl Chloroformate and Ethyl Chlorothioformate. J. Org. Chem. 1998, 63, 2120-2124.

59. Kevill, D.N.; D’Souza, M.J. Dual Pathways in the Solvolyses of Phenyl Chlorothioformate. J. Org. Chem. 1997, 62, 7869-7871.

60. Kevill, D.N.; D'Souza, M.J. Correlation of the Rates of Solvolysis of Phenyl Chlorothionoformate and Phenyl Chlorodithioformate. Can. J. Chem. 1999, 77, 1118-1122.

61. Kevill, D.N.; Koyoshi, F.; D’Souza, M.J. Correlation of the Specific Rates of Solvolysis of Aromatic Carbamoyl Chlorides, Chloroformates, Chlorothionoformates, and Chlorodithioformates Revisited. Int. J. Mol. Sci. 2007, 8, 346-352.

62. Kevill, D.N.; D'Souza, M.J. Correlation of the Rates of Solvolysis of Phenyl Chloroformate. $J$. Chem. Soc. Perkin Trans. 2 1997, 1721-1724. 
63. Koo, I.S.; Yang, K.; Kang, D.H.; Park, H.J.; Kang, K.; Lee, I. Transition-State Variation in the Solvolyses of Phenyl Chlorothionoformate in Alcohol-Water Mixtures. Bull. Korean Chem. Soc. 1999, 20, 577-580.

64. An, S.K.; Yang, J.S.; Cho, J.M.; Yang, K.; Lee, P.L.; Bentley, T.W.; Lee, I.; Koo, I.S. Correlation of the Rates of Solvolysis of Phenyl Chlorodithioformate. Bull. Korean Chem. Soc. 2002, 23, 1445-1450.

65. Kevill, D.N.; Kim, J.C.; Kyong, J.B. Correlation of the Rates of Methyl Chloroformate with Solvent Properties. J. Chem. Res. Synop. 1999, 150-151.

66. D’Souza, M.J.; Stant-Boggs, M.E.; White, R.; Kevill, D.N. Correlation of the Rates of Solvolysis of 2-Thiophenecarbonyl Chloride. J. Chem. Res. (S) 2003, 12, 775-777.

67. D'Souza, M.J.; Bogg, M.E.; Kevill, D.N. Correlation of the Rates of Solvolysis of 2Furancarbonyl Chloride and Three Naphthoyl Chlorides. J. Phys. Org. Chem. 2006, 19, 173-178.

68. Kevill, D.N.; D’Souza, M.J. Additional $Y_{\mathrm{Cl}}$ Values and Correlation of the Specific Rates of Solvolysis of tert-Butyl Chloride in Terms of $N_{\mathrm{T}}$ and $Y_{\mathrm{Cl}}$ Scales. J. Chem. Res. Synop. 1993, 174-175.

69. Seong, M.H.; Choi, S.H.; Lee, Y.-W.; Kyong, J.B.; Kim, D.K.; Kevill, D.N. Correlation of the Rates of Solvolysis of Methyl Fluoroformate Using the Extended Grunwald-Winstein Equation. Bull. Korean Chem. Soc. 2009, 30, 2408-2412.

70. Bentley, T.W.; Llewellyn, G.; McAlister, J.A. $\mathrm{S}_{\mathrm{N}} 2$ Mechanism for the Alcoholysis, Aminolysis, and Hydrolysis of Acetyl Chloride. J. Org. Chem. 1996, 61, 7927-7932.

71. Romano, R.M.; Della Védova, C.O.; Downs, A.J. Matrix Photochemistry of the Chlorocarbonyl Sulfenyl Compounds $\mathrm{ClC}(\mathrm{O}) \mathrm{SY}$, with $\mathrm{Y}=\mathrm{Cl}$ or $\mathrm{CH}_{3}$. J. Phys. Chem. A 2004, 108, 7179-7187.

72. Kevill, D.N.; Park, B.-C.; Park, K.-H.; D’Souza, M.J.; Yaakoubd, L.; Mlynarski, S.L.; Kyong, J.B. Rate and Product Studies in the Solvolyses of $N, N$-Dimethylsulfamoyl and 2-Propanesulfonyl Chlorides. Org. Biomol. Chem. 2006, 4, 1580-1586.

73. Frost, A.A; Pearson, R.G. Kinetics and Mechanism-a Study of Homogeneous Chemical Reactions, 2nd ed.; Wiley: New York, NY, USA, 1961; pp. 49-50.

74. Kevill, D.N.; Abduljaber, M.H. Correlation of the Rates of Solvolysis of Cyclopropylcarbinyl and Cyclobutyl Bromides Using the Extended Grunwald-Winstein Equation. J. Org. Chem. 2000, 65, 2548-2554.

(C) 2010 by the authors; licensee MDPI, Basel, Switzerland. This article is an Open Access article distributed under the terms and conditions of the Creative Commons Attribution license (http://creativecommons.org/licenses/by/3.0/). 